\title{
Bacteriological Study of Eye infection in Baghdad City
}

\author{
Farah Ali Hameed \\ Lecturer, Middle Technical university, Institute of Medical Technology/ Baghdad/ Nursing Department, Iraq;
}

\begin{abstract}
The present study included 250 clinical samples during the period between December 2018 - April 2019 on 250 patients with ophthalmological infections of both sexes \& different ages ( 3 days - 75 years old), attend to ophthalmological clinic in hospital Ibn-AL-Hythem for eyes infection in Baghdad. The ophthalmological infections classified into 3 types according to the anatomical site of involvement. The first group was conjunctivitis(200)case, the 2 nd was Blepharitis (35) case $\&$ the 3 rd was Keratitis ( 15) cases. Isolation of the causative micro-organisms for the previous infections, culture \& sensitivity test to different antimicrobial agents were done. The results showed that 200(229.4)\% are you giren significant growth of bacteria while 50(69.07\% ) were no growth for bacteria . Include Staphylococcus aureus(77.6\%),Staphylococcus epidermidis (13.6\%), Streptococcus pneumonia $(6.4 \%)$ \& Streptococcus pyogenes $(2.1 \%)$, while G-ve isolates 61(30.5\%) include (7) species of bacteria ; Haemophilus influenzae(81.9\%), Klebsiella pneumonia(6.5\%), Proteus spp \& Pseudomonas aeruginosa, the Same (3.2\%) for each \& finally Neisseria gonorrhoeae, Moraxella spp, Acinetobacter were the least (1.6\%) for each. Antimicrobial (12 agents) susceptibility of the bacterial isolates revealed marked resistant of these isolates for most antimicrobial agents e.g. Penicillin (87.8\%),amoxicillin/clavulanicacid(84.4\%), cephalexien(83.9\%), erythromycin(83.4\%), ampicillin (71.3\%) while the least resistant $(8.2 \%)$ reported for ciprofloxacin.
\end{abstract}

Keyword: Eye infection, Bacteria, Resistance Antibiotics, Baghdad.

\section{Introduction}

The eye is the most exposed part in the body to the air which carries dust and microorganisms such as bacteria and fungi causing infections to the eye, especially when any scratch or wound occurs in the lining tissues of the eye, as these microorganisms quickly settle into the broken tissues, causing significant eye damage [1], including conjunctivitis which is called "red eye" or "pink eye" which involves inflammation of the soft layer that covers the sclera of the eye and this disease may affect one eye or may spread to the other eye ${ }^{[2] . ~ K e r a t i t i s ~ m a y ~ f o r m ~ h o l e s, ~ m o s t ~ l i k e l y ~ r e s u l t i n g ~}$ from conjunctivitis and the spread of toxins produced by the microorganisms that cause these conditions ${ }^{[3]}$. While blepharitis caused by microorganisms, and the injury may be external if it is outside the line between the inside and outside the eye, or internal when it is on the inner surface of the eyelids [4]. These infections occur despite the eye's resistance to external influences through various mechanisms such as wetting by tears containing the bactericidal lysozyme enzyme, mucous membrane and eyelid movement ${ }^{[5]}$, as this resistance may weaken people suffering from certain diseases such as malignant tumors and organ transplantation, as well as people who take antibiotics or cortisones for long times, drug addicts, or diabetic and AIDS patients ${ }^{[6]}$.

Bacterial types that may cause eye infections include Staphylococcus aureus, Staphylococcus epidermidis, Bacillus subtilis, Bacillus cereus, Pseudomonas aeruginosa, Neisseria gonorrhea, Moraxella spp. , Streptococcus pneumonia, Hemophilus influenza and Acinetobacter etc ${ }^{[7]}$. Eye infections are often treated by antibiotics before performing the antibiotic sensitivity test, therefore, broad spectrum antibiotics such as ciprofloxacin, ofloxacin, chloramphenicol, tetracyclin, erythromycin and gentamycin are used for treatment [8]. As a result of the wide and random use of these antibiotics, the microorganisms showed resistance leading to the appearance of spontaneously mutated bacterial isolates with high ability to resist antibiotics ${ }^{[9]}$, or due to the bacterial plasmids which are responsible for antibiotic resistance as there are conjugative plasmids 
having the ability to transfer from one bacteria to the other within the same species or even from anßother bacterial genera, and their transmission will lead to the appearance of resistance characteristics among these isolates [10], or the reason for the resistance may be the change of the target location to the antibiotic so that the antibiotic loses its effect on the microorganism or as a result of the production of $\beta$-lactamase enzymes which destroy destroy the anti $\beta$-lactum antibiotics, including Penicillins and Cephalosporins. $\beta$-lactum antibiotics ${ }^{[11]}$.

\section{Materials and Method}

\section{Sample collection}

From patients who visited the ophthalmic consultative clinic in hospital Ibn-AL-Hythem for eyes infection in Baghdad 250 clinical samples were collected from three parts of the eyes (the conjunctiva, the cornea and the eyelids). The patients included both males and females with less than 75 years of age for the period from December 2018 to April 2019. A special form was prepared for each patient in which some important information such as age, gender, type of work, residence and antibiotic use were recorded. All patients were clinically examined by specialist doctors. Samples were collected by sterile cotton swabs containing transport media, and transferred to the hospital's laboratory for culturing on blood, MacConkey and chocolate agars, then incubated for 24 hours at $37 \mathrm{C}^{0}{ }^{[12]}$. Bacterial isolates were then diagnosed depending on morphologic al characteristics including( colony size, color, edge and height). After that, thin smears were prepared from these isolates and stained with Gram stain to observe bacterial ability to stain and study their shapes and arrangements, and diagnosed by using the biochemical tests as mentioned by ${ }^{[13]}$. The diagnosis was confirmed by using the Api 20 Staph for Staphylococci, Api 20 Strept. for Streptococci and Api 20 E for the diagnosis of Enterobacteriace.

\section{Antibiotic sensitivity test of bacteria}

The disc diffusion method was used to perform the antibiotic sensitivity test for the bacterial isolates, by using 12 antibiotic discs according to the method of Brook, et al [14], as a part of the pure colonies was transferred into test tubes containing $5 \mathrm{ml}$ of liquid Muller Hinton and incubated at 37C for 24 hours. The growth was diluted, when necessary, with normal saline until the turbidity became homogenous with the turbidity of the solution in McFarland tube, which gives approximate number of cells about $\left(1.5 \times 10^{8}\right)$ cells $/ \mathrm{ml}$. Then the cotton swabs were introduced into the tubes containing bacterial growth, and the excess was removed by pressure on the inner walls of the test tubes, and swabs were streaked on the surfaces of solid Muller Hinton media in different directions to ensure equal spread of bacteria, followed by placing 12 antibiotic discs including Vancomycin, Neomycin, Ciprofloxacin, Erythromycin, Cephalixein, Gentamycin, Amoxocillin/Clavulanic acid, Penicillin, Ampicillin, Chloramphenicol, Cefotaxim and Tetracycline) provided by Bioanalysis company (Turkey), on the surface of the culture media which was inoculated with the bacterial culture by using sterile forceps that were pressed gently on the antibiotic discs. The plates were incubated for 24 hours at $37 \mathrm{C}$ and the results were compared by measuring the growth inhibition area around the antibiotic discs, and results were explained according to CLSI ${ }^{[1]}$.

\section{Results and Discussion}

\section{Isolation and identification of bacteria}

Results of this study showed that 200 (229.4\%) samples yielded bacterial growth, while $50(69.07 \%)$ samples showed no bacterial growth after clinical diagnosis by specialist doctor. All the studied patients were suffering from conjunctivitis, keratitis and eye inflammation as shown in table (1). Negative microbial infections may be attributed to bacteria and fungi other than those included in our study such as chlamydia, fungi, viruses and parasites or because of allergy ${ }^{[15]}$, The all these samples were cultured on selective media and confirm identification by biochemical tests as shwn in table (1)that refer to growth bacteria indifferent percentage 
Table (1): Percentage of bacterial growth in eye infeaction parts of the eye

\begin{tabular}{|c|c|c|c|c|c|}
\hline \multirow{2}{*}{ Infected area } & \multirow{2}{*}{$\begin{array}{l}\text { No. of } \\
\text { samples }\end{array}$} & \multicolumn{2}{|c|}{$\begin{array}{l}\text { No. of samples which gave } \\
\text { positive results to }\end{array}$} & \multirow{2}{*}{$\begin{array}{l}\text { No. of samples } \\
\text { which gave negative } \\
\text { bacterial growth }\end{array}$} & \multirow{2}{*}{ Percentage } \\
\hline & & $\begin{array}{l}\text { Bacterial } \\
\text { growth }\end{array}$ & percentage & & \\
\hline Conjunctivitis & 200 & 159 & 79.5 & 41 & 20.5 \\
\hline Eyelid infection & 35 & 32 & 91.4 & 3 & 8.57 \\
\hline Keratitis & 15 & 9 & 60 & 6 & 40 \\
\hline Total & 250 & 200 & 229.4 & 50 & 69.7 \\
\hline
\end{tabular}

The isolates involved 11 Gram positive and Gram negative bacterial types, as the Gram +ve bacteria were $139(69.5 \%)$ isolates distributed into $77.6 \%$ S. aureus, $13.6 \%$ S. epidermidis, $6.4 \%$ St. pneumonia and $2.1 \%$ St. pyogenes, while the number and percentage of Gram -ve bacteria were $61(30.5 \%)$ including 7 types of bacteria distributed as Hemophilus influenza (81.9\%), while the percentage of Klebsiella pneumonia (6.5\%), and each of Pseudomonas and Proteus spp. were (3.2\%) While all of the bacteria Neisseria gonorrhoeae, Moraxella. sppand Acinetobacter.spp The lowest percentages were $1.6 \%$ as shown in table (2). Our results were almost close to those of Al-Sabaawi (2005) who isolated S. aureus, S. epidermidis, Bacillus subtilis, Bacillus cereus, Pseudomonas aeruginosa, N. gonorrhea and Moraxella spp. in the percentage of $(51,3.2,19.8,8.3,5.2,1$ and $11.5)$ respectively.

The increase of S. aureus infection may be attributed to their normal existence on the skin and air and even in the eyes as micronormal flora and they may become pathogenic under certain conditions such as immunocompromised patients with chronic diseases as these bacteria can cause infections to the conjunctiva, cornea and eyelids or they may be transmitted by contaminated hands as well as having virulence factors such as enzymes and toxins e.g. protease and lipase [16]. S. epidermidis is a normal flora of the skin but they can cause infection to immunocompromised hosts ${ }^{[17]}$. Streptococcus spp. also causes eye infections. In a study done by ${ }^{[4]}$, they could isolate $(9 \%)$ of $S$. pneumonia from conjunctivitis conditions. Both of $H$. influenza and Proteus vulgaris were found to cause eye infections, as well as Pseudomonas aeruginosa due to its widelydistribution in environment and its ability to adapt and secrete protease and collagenase enzymes causing conjunctivitis and secondary keratitis. Other causes of eye infection is $N$. gonorrhea bacteria which may lead to blindness. It infects newborns since it is transmitted from the infected mother to her baby because it infects the reproductive system ${ }^{[14,18]}$.

Table (2): Bacteria isolated from infected eyes

\begin{tabular}{|l|l|l|l|}
\hline No. & Causative agent & No. of isolates & Percentage \\
\hline \multirow{4}{*}{$\mathbf{1}$} & Gram positive bacteria: & & \\
& S. aureus, & 108 & 77.6 \\
& S. epidermidis & 19 & 13.6 \\
& St. pneumonia & 9 & 6.4 \\
& St. pyogenes & 3 & 2.1 \\
\hline & Total number & $\mathbf{1 3 9}$ & $\mathbf{6 9 . 5}$ \\
\hline
\end{tabular}


Cont... Table (2): Bacteria isolated from infected eyes

\begin{tabular}{|l|l|l|l|}
\hline \multirow{5}{*}{2} & & & 81.9 \\
& Gram negative bacteria & 50 & 6.5 \\
& H. influenza & 4 & 3.2 \\
& Klebsiella pneumonia, Pseudomonas & 2 & 3.2 \\
& aeruginosa, Proteus spp. & 2 & 1.6 \\
& N. gonorrhea & 1 & 1.6 \\
& Acetinobacter .spp & 1 & 106 \\
\hline & Moraxella .spp & 1 & 30.5 \\
\hline & Total number & 61 & 100 \\
\hline
\end{tabular}

\section{Antibiotics sensitivity test}

Antibiogram test was carried out by using different types of antibiotics and results showed different levels of resistanceas shown in table(3). Gram +ve bacteria, represented by $S$. aureus, S. epidermidis, St. pneumonia and St. pyogenes showed different resistances to the antibiotics where $\mathrm{S}$. aureus showed the highest resistance rate to the cephalexein and penicillin (92.5 and 91.6) respectively, while these bacteria showed the highest sensitivity rate to ciprofloxacin (7.4\%). Regarding S. epidermidis bacteria, the results revealed that they showed the highest resistance rate to cephalexein (89.4\%), while they showed the lowest resistance rate to the antibiotics ampicillin, ciprofloxacin and vancomycin (21\%) for each one.

The result on the sensitivity of S.aureus to ciprofloxacein were close to the results of Barid ${ }^{[4]}$ who found that the resistance of these bacteria was low to the antibiotic, however, they showed high resistance to Penicillin. Marlin [26], in his study, also found that ciprofloxacin was very active against $S$. aureus strains, because this antibiotic inhibits bacterial growth through the inhibition of DNA gyrase enzyme which is responsible for spiral recoiling of DNA and insures their being apart during transcription process.

While both St. pneumonia and St. pyogenes also showed different responses to these antibiotics. In table (3), it is observed that St. pneumonia showed the highest resistance rate $(88.8 \%)$ to amoxocillin/clavulanic acid, penicillin, ampicillin and tetracycline, while it showed the highest sensitivity rate $(100 \%)$ aginst ciprofloxacin. Streptococcus pyogenes showed (100\%) resistance to Penicillin, while the lowest resistance rate $(33.3 \%)$ was to the antibiotics ciprofloxacin, cefotaxime, chloramphenicol, neomycin, Gentamycin and vancomycin.

Gram negative bacteria isolated in our study showed different responses to antibiotics (table 3). Hemophilus influenza showed (100\%) resistance to Amoxocillin/ Clavulanic acid, while the lowest resistance rate (7.4\%) was to ciproflaxocin and cephotaxim, whereas Klebsiella pneumonia showed (100\%) resistance to amoxocillin/ clavulanic acid, penicillin, Ampicillin, erythromicin, vancomycin, tetracyclin and chloramphenicol, but it was sensitive to ciprofloxacin.

Pseudomonas aeruginosa showed (100\%) resistance to Amoxocillin/Clavulanic acid, but showed no resistance to Ciprofloxacin.

The result in table (3) demonstrated that $N$. gonorrhea were (100\%) resistance to amoxocillin/ clavulanic acid, penicillin, ampicillin, vancomycin and cephalexein, and showed no resistance to penicillin, cephotaxime, Neomycin, gentamycin, ciprofloxacin, erythromycin, chloramphenicol and tetracycline. my results agreed with ${ }^{[4]}$ in regard to the highly sensitivity of Erythromycin to all N. gonorrhea isolates.

Moraxella spp. showed (100\%) resistance to amoxocillin, penicillin, ampicillin, cephalexin , cephotaxime and tetracycline, but showed no resistance to neomycin, gentamycin, ciprofloxacin, erythromycin, 
vancomycin and chloramphenicol. my results agreed with ${ }^{[3]}$ on the effectiveness of Chloramphenicol as a broad spectrum antibiotic with a high activity against Moraxella spp.

It was also shown that Proteus spp. showed (100\%) resistance to penicillin, cephotaxime, tetracycline and chloramphenicol, but showed no resistance to ciprofloxacin, cephalexin and gentamycin, which agreed with ${ }^{[4]}$ about the effect of cephotaxime, chloramphenicol and tetracycline on Proteus spp. which showed (100\%) resistance to these antibiotics.

\section{Conclusion}

The concluded from This study that Ciprofloxacin was the most effective antibiotic on the studied bacteria, and this may be explained by the fact that local isolates didn't develop high resistance to this antibiotic due to its limited use in comparison with Penicillin and also because Ciprofloxacin is a broad spectrum antibiotic.

Financial Disclosure: There is no financial disclosure.

Conflict of Interest: None to declare.

Ethical Clearance: All experimental protocols were approved under the Institute of Medical Technology and all experiments were carried out in accordance with approved guidelines.

\section{References}

1. Thomas P A. Mycotic keratitis, an underestimated mycosis, J Med. Vet. Mycol, 2003;32: 235-56.

2. Macsween C. Cataracts. Net Doctor. Co. UK. 2004.

3. Chen W L, Wang I J, Hu F R. Microbial keratitis. Am. J. Ophthalmol. 2004; 137(4): 736743.

4. APD Majed kadem AL -Shably. Isolation of bacteria that cause eye infection and Identification Diwaniya city . College of Education/ Biology. 2011.

5. Songer J G, Post K W. Veterinary microbiology. Bacterial and fungal agents of animal diseases. Elsevier Saunders publishing company. 2005.

6. Hsueh P, Teng L, Chen C, Chen W Yu C, H S. luh..Pandrug-resistant Acinetobacter baumannii causing nosocomial infections in a university hospital, Taiwan. Emerging Infec. Dis. 2002;8(8).
7. Al-Sabawi, Rana Ibrahim Mohamed Abdullah . Isolation and diagnosis Moraxella catarrhalis. From ophthalmitis and studying some of its virulence factors, Master's thesis, Faculty of Sciences University of Mosul.2005.

8. Idu F K, Odjimogho S E. Susceptibility of conjunctival bacterial pathogens to Fluoroquinolones: A comparative study of Ciprofloxacin, Norfloxacin and Ofloxacin. Online J. Health Allied Scien. 2003; 2 (3): 1.

9. Jawetz E J, Melnick J L, Adelberg E A, Brooks G F, Butel J S, Morse S A. Medical Microbiology ,23rded.Appelton and Longe .USA. 2004.

10. Sleigh J D, Timbury M G. Medical Bacteriology. 5th ed., Churchill Livingstone., New York. 1988.

11. Nass T h, Benaoadia F, Massuard S, Nordmann P. Intergron located VEB1 extended spectrum -Lactamase gene in Proteus mirabilis clinical isolated from Vietnam. J. Antimicrob. Chemotherapy, 2000;46: 703-711.

12. Collee J G, Fraser A G, Marmion B P, Simmons A. Mackie \& McMarteny. Practical Medical Microbiology.14th.ed. Churchill Livingstone Inc., New York, U.S.A. 1996.

13. Alexander S K, Strete D, Niles M J. Laboratory Exercises in Organismal \& Molecular Microbiology .The McGraw -Hill Companies .USA8. 2004 .

14. Brooks G F, Butel J S, Morse S A. Jawtz Melnck and Adelberg's Medical Microbiology. 21th ed. Appelton and Lange. California. 1998.

15. Martinez B O, Ruiz R M, Perez R M. Bacterial conjunctivitis: prevalence of most pathogens and susceptibility to antibiotics. Antimicrob. Agents Chemother. 2004;61 (1): $32-36$.

16. Brooks G F, Butel J S, Morse S A. Jawetz, Melnick, \& Adelberg's Medical Microbiology. 22ed. A Division of the McGraw-Hill Companies. 2001.

17. Leid J G, Costerton W J, Shirtliff M E, Gilmore M S. Engelbert M. Immunology of staphylococcal Biofilm infections in the Eye: New Tools to study Biofilm Endophthalmitis. Mary. Ann. 2002;21(56): 405-413.

18. Vuong C. \& Otto, M. Staphylococcus epidermidis infections. Microbes. Infect. 2002;4(4): 481-489.

19. Marlin D S. Bacterial conjunctivitis. e-medicine, Patient plus, 10 - 11.(http//www.Patient.co.uk.). 2003. 
20. Modarres S H, Lasheii A, Oskoii N N. Bacterial etiologic agents of ocular infection in the Islamic Republic of Iran. Am. J. Ophthalmol. 1998;4 (1): $44-49$.

21. Martinez B O, Ruiz R M, Perez R M. Bacterial conjunctivitis: prevalence of most pathogens and susceptibility to antibiotics. Antimicrob. Agents Chemother. 2004;61 (1): $32-36$.

22. Alexander S K, Strete D, Niles M J. Laboratory Exercises in Organismal \& Molecular Microbiology .The McGraw -Hill Companies .USA8 .2004.

23. Macsween C. Cataracts. Net Doctor. Co. UK. 200

24. Tabbara K F, Sheikh H F, Aabed B. Extended wear contact lens related bacterial keratitis. Br. J. Ophthalmol. 2000; 84 (3): 327-328.
25. David L, Paterson C W, Gttberg A V, Casellas J M, Mulazimoglu L, Klugman K P, Bonomo R A, Rice L B. Outcome of cephalosporin treatment for serious infections due to apparently susceptible organisms producing extended spectrum $\beta$ lactamase .J. Clin. Microbiol . 2001;39:2206-2212 .

26. Prescott L M. Microbiology .5th ed .The McGrawHill Companies.USA. 2002.

27. Anagaw B, Fantahun B, Berhanu A, Yeshambel B, Andargachew M. Bacteriology of ocular infections and their antibiotic susceptibility pattern in Gondar University Hospital, North West, Ethiopia. Ethiop. Med. J. 2011;49(2): 11723. 